Corrigendum

\title{
Corrigendum to "Comparison of Different Strategies for Selection/Adaptation of Mixed Microbial Cultures Able to Ferment Crude Glycerol Derived from Second-Generation Biodiesel”
}

\author{
C. Varrone, ${ }^{1,2}$ T. M. B. Heggeset, ${ }^{3}$ S. B. Le, ${ }^{3}$ T. Haugen, ${ }^{3}$ \\ S. Markussen, ${ }^{3}$ I. V. Skiadas, ${ }^{1,2}$ and H. N. Gavala ${ }^{1,2}$ \\ ${ }^{1}$ Department of Chemistry and Biosciences, Aalborg University, 2350 Copenhagen, Denmark \\ ${ }^{2}$ Department of Chemical and Biochemical Engineering, Technical University of Denmark, 2800 Lyngby, Denmark \\ ${ }^{3}$ Biotechnology and Nanomedicine, SINTEF Materials and Chemistry, 7465 Trondheim, Norway
}

Correspondence should be addressed to C. Varrone; cristiano.varrone@gmail.com

Received 9 November 2016; Accepted 22 January 2017; Published 6 February 2017

Copyright (C) 2017 C. Varrone et al. This is an open access article distributed under the Creative Commons Attribution License, which permits unrestricted use, distribution, and reproduction in any medium, provided the original work is properly cited.

In the article titled "Comparison of Different Strategies for Selection/Adaptation of Mixed Microbial Cultures Able to Ferment Crude Glycerol Derived from Second-Generation Biodiesel" [1], there is a systematic error in the yields reported (in $\mathrm{g} / \mathrm{g}$ ) in section "3.1.1. Activated Sludge." It is reported again in section "4. Conclusions." These yields need to be divided by a factor of 10 , due to a conversion mistake. This does not alter or affect the discussions and conclusions that have been reached in this paper, since the scope was to make a comparison among the different mixed cultures obtained.

\section{References}

[1] C. Varrone, T. M. B. Heggeset, S. B. Le et al., "Comparison of different strategies for selection/adaptation of mixed microbial cultures able to ferment crude glycerol derived from secondgeneration biodiesel," BioMed Research International, vol. 2015, Article ID 932934, 14 pages, 2015. 

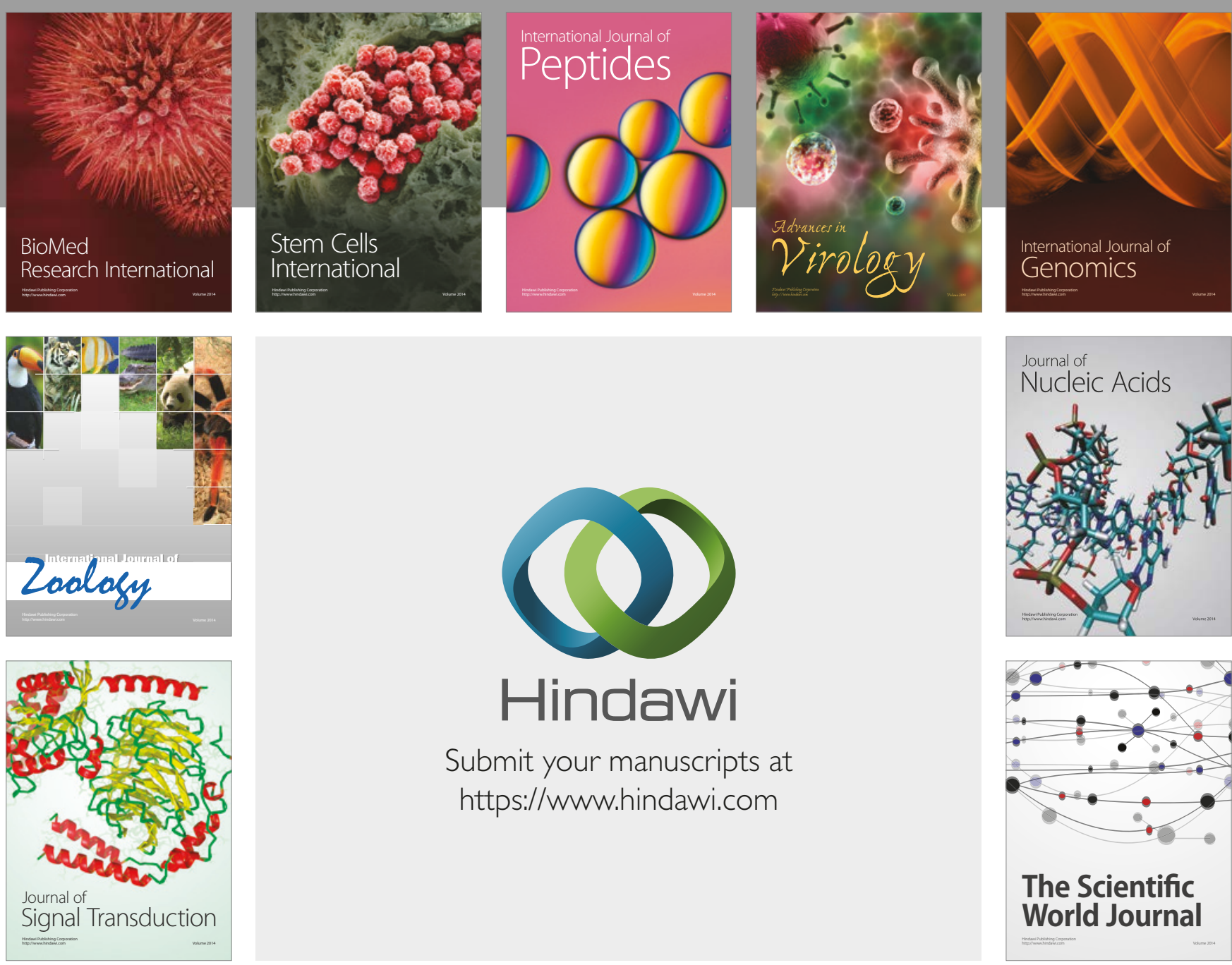

Submit your manuscripts at

https://www.hindawi.com
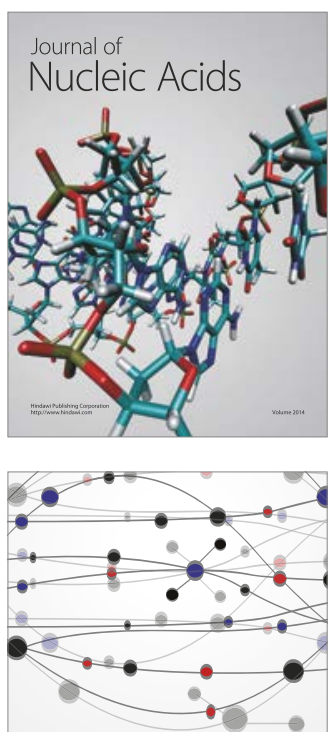

The Scientific World Journal

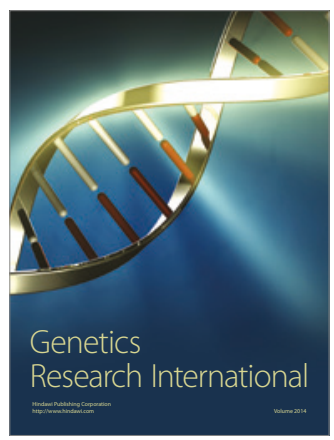

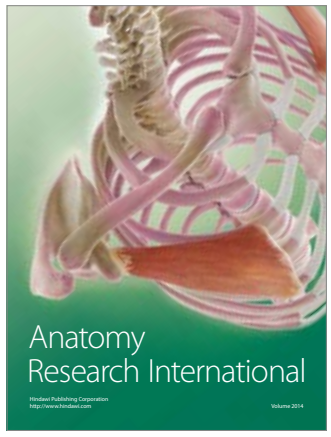

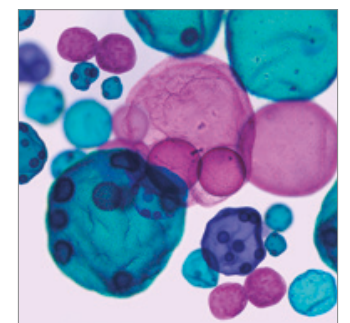

International Journal of Microbiology
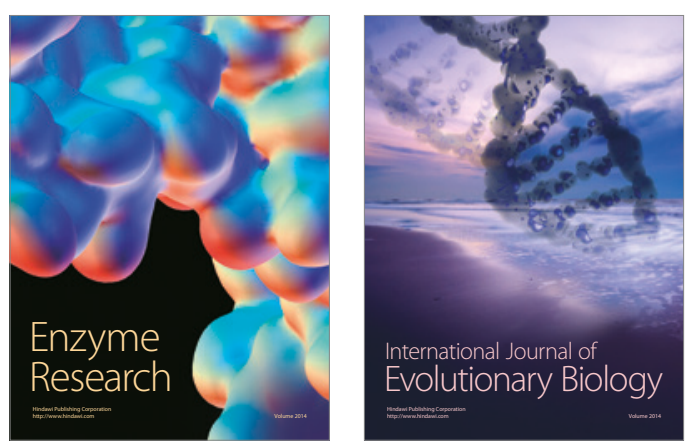
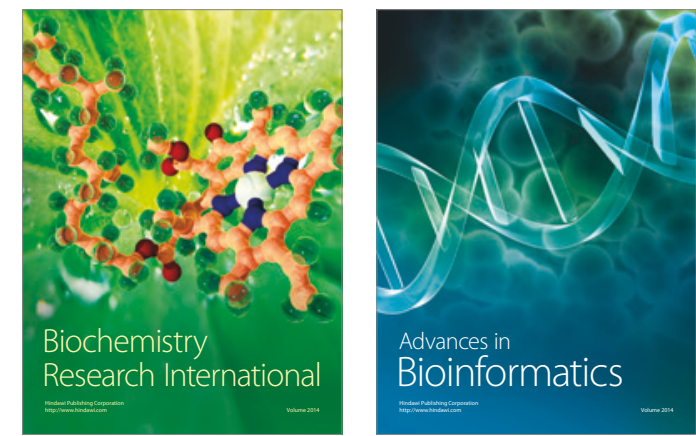

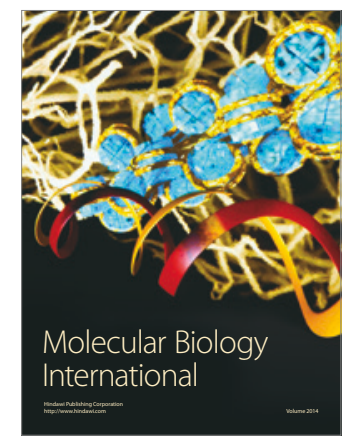

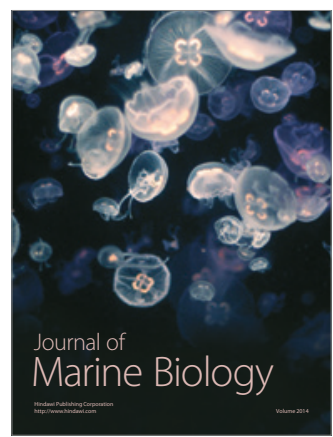

